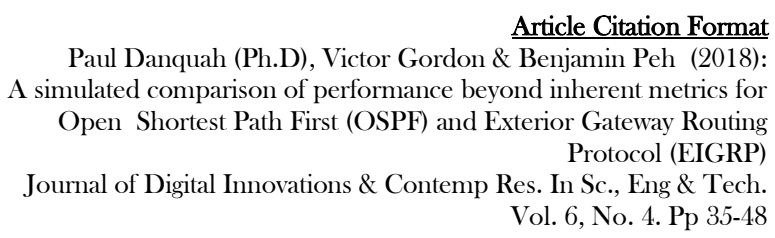

Article Citation Format

Paul Danquah (Ph.D), Victor Gordon \& Benjamin Peh (2018): A simulated comparison of performance beyond inherent metrics for Open Shortest Path First (OSPF) and Exterior Gateway Routing Protocol (EIGRP) Journal of Digital Innovations \& Contemp Res. In Sc., Eng \& Tech. Vol. 6, No. 4. Pp 35-48

\begin{tabular}{|r|}
\hline Article Progress Time Stamps \\
Article Type: Research Article \\
Manuscript Received: $7^{\text {th }}$ Oct. 2018 \\
Review Type: Blind \\
Final Acceptance:: $29^{\text {th }}$ Nov, 2018 \\
DOI Prefix: 10.22624 \\
\hline
\end{tabular}

\title{
A simulated comparison of performance beyond inherent metrics for Open Shortest Path First (OSPF) and Exterior Gateway Routing Protocol (EIGRP)
}

\author{
Paul Danquah (Ph.D), Victor Gordon \& Benjamin Peh \\ Council for Scientific and Industrial Research \\ Institute for Scientific and Technological Information \\ Accra, Ghana \\ Email: pauldanquah@yahoo.com
}

\begin{abstract}
The research paper empirically compares the two routing protocols Open Shortest Path First (OSPF) and Enhanced Interior Gateway Routing Protocol (EIGRP) to determine which of the two performs better beyond their inherently known metrics. A simulated environment was developed with a network setup to test and compare overall throughput of data transmission output in the contextual implementation of either routing protocols. The results of the experiment showed that EIGRP provides faster transmission and response times as compared to OSPF implementation under the simulated environment in the event that all conditions are equal. This may not be absolute in varying scenarios, however, compared to earlier research work done on different topologies but same routing protocols, this research output confirms the notion that EIGRP performs better than OSPF on performance basis beyond inherent metrics.
\end{abstract}

Keywords: EIGRP, OSPF, Performance Based Routing, Routing Protocols, Dynamic Routing

\section{INTRODUCTION}

In modern large-scale networks, dynamic routing protocols are used more often than static routing, the most effective and efficient routing protocol is needed to support modern network on a large scale. A dynamic routing protocol may be implemented to reduce administrative work and also make room for easy growth of the network. Dynamic routing requires the implementation of routing protocols, a routing protocol is the set of rules by which routers share information about the reachability and status of networks. Various routing protocols have their own inherent routing metrics that is comparable and can be used as a basis for choice. This research sets out to compare routing protocols based on results obtained from tests carried out beyond the inherent metrics of the routing protocols. Specifically, network round trip times and time to live are used to compare the protocols on the basis of message round trip and time to live for packets transmitted. The typical criteria typically includes procedure to select the best path based on the reachability information in a route table. This procedure is based on routing metrics which is determined via a specific routing algorithm of the routing protocol in use [1]. 
The routing metrics are used to determine a ranking of paths to a remote destination from the most preferred to least preferred. The metrics range from hop counts, costs, routing convergence, scalability and other factors. Routing protocols share information first among immediate neighbors, and then throughout the network. This way, routers gain knowledge of the topology of the network.

\subsection{Objective}

The objective of this research is to compare the OSPF and EIGRP routing protocols based on results obtained from performance tests carried out beyond the inherent metrics of the respective routing protocols. Specifically, network round trip times and time to live are used to compare the protocols on the basis of message round trip and time to live for packets transmitted.

\section{LITERATURE REVIEW}

Large-scale networks typically have many autonomous systems, dynamic routing protocol used more often than static routing protocol. The most effective and efficient routing protocol is needed to support modern network on a large scale. The research that have been done among other entitled Performance Evaluation of Routing Protocol RIP, OSPFv3, and EIGRP IPv6 Networking discuss the comparison between internal routing protocol with the parameters of throughput, jitter, and packet loss. "The results of this research indicate that the OSPF routing protocol has the smallest value of network convergence. Then a combination of routing protocol OSPF-BGP has the highest throughput, lowest packet loss, and smallest jitter value" [1]. A similar research conducted showed that EIGRP protocol provides a better performance than OSPF routing protocol for real time applications. [2]. Types of Routing Protocols: Theoretically, routing protocols are classified into distance vector and link state. "Distance vector routing protocol is based on Bellman - Ford algorithm and Ford - Fulkerson algorithm to calculate paths" [3]. A distance vector routing protocol uses a distance calculation and a vector direction of next hop router as reported by neighboring routers to choose the best path. It requires that a router informs its neighbors of topology changes periodically. "Link state routing protocols build a complete topology of the entire network are and then calculating the best path from this topology of all the interconnected networks". It requires more processing power and memory because it has a complete picture of the network [4].

Classful and Classless Routing Protocols: The classful routing protocols are routing protocols that do not carry the subnet mask information within the routing updates. In addition, classful routing protocols require that every interface and host on the network must use the same subnet mask. These routing protocols waste more address spaces and also sending out periodic routing updates to all active interface of each router causing congestion on the slower Wide Area Network (WAN) links [5]. Classless routing protocols are routing protocols that include the subnet mask information when the routing tables or updates are exchanged. Classless routing protocols allow using the networks with the different length of subnet masks thus supporting Classless Inter-Domain Routing (CIDR) and Variable Length Subnet Mask (VLSM).”Classless routing protocols exchange the entire routing table with the neighbor routers only at the very first time and routing updates are sent only when changes occur in the network topology"[6]. This significantly reduces bandwidth consumption.

\section{Static and Dynamic Routing}

Routing may be done statically or dynamically, Static routing is the process of manually entering routes into a device's routing table. In static routing, all the changes in the logical network layout need to be manually done by the system administrator. Dynamic routing on the other hand automatically gathers routing paths from other connected routers and determines the best path when there is a real time logical network layout change. Dynamic routing protocols are further categorized into Interior Gateway Protocols (IGP) distance vector, IGP link-state and Exterior Gateway Protocols (EGP). Typical examples are Routing Information Protocol, Open Shortest Path First and Border Gateway Protocol[7]. 


\section{The Routing Protocols in Context}

Enhanced Interior Gateway Routing Protocol (EIGRP) is an advanced distance-vector routing protocol that is used on a computer network for automating routing decisions and configuration. "The protocol was designed by Cisco Systems as a proprietary protocol. EIGRP is used on a router to share routes with other routers within the same autonomous system"[7]. EIGRP only sends incremental updates, reducing the workload on the router and the amount of data that needs to be transmitted. Almost all routers contain a routing table that contains rules by which traffic is forwarded in a network. EIGRP uses the neighbour, topology and routing table to store information following tables to store information. When a router running EIGRP is connected to another router also running EIGRP, information is exchanged between the two routers and a relationship is formed known as an adjacency. "The entire routing table is exchanged between both routers at this time. After this has occurred, only differential changes are sent"[8]. EIGRP is often considered a hybrid protocol because it is also sends link state updates when link states change. EIGRP is commonly used in large networks, and it updates only when a topology changes but not periodically unlike old Distance-Vector protocols such as RIP.

Metric is used to determine whether the chosen route is optimized. EIGRP metric is based on its bandwidth, delay, reliability, load and MTU. Open Shortest Path First (OSPF) is defined in RFC 2328 which is an interior Gateway Protocol used to distribute routing information within an AS (Autonomous System). "Among all the three chosen samples, OSPF is the most widely used routing protocol in large enterprise networks. OSPF is based on link-state technology by using SPF algorithm which calculates the shortest path" [9].

\section{Shortest Path First Calculation}

Before running the calculation, it is required that all routers in the network to know about all the other routers in the same network and the links among them. The next step is to calculate the shortest path between each single router. For all the routers they exchange link-states which would be stored in the link-state database. Every time a router receives a link-state update, the information stores into the database and this router propagate the updated information to all the other routers. Routing Information Protocol (RIP): This is a distance-vector routing protocols which employs the hop count as a routing metric. RIP prevents routing loops by implementing a limit on the number of hops allowed in a path from source to destination. The largest number of hops allowed for RIP is 15 , which limits the size of networks that RIP can support. RIP implements the split horizon, route poisoning and holddown mechanisms to prevent incorrect routing information from being propagated. In RIP router broadcast updates with their routing table every 30 seconds.

In the early deployments, routing tables were small enough that the traffic was not significant. "As networks grew in size, however, it became evident there could be a massive traffic burst every 30 seconds, even if the routers had been initialized at random times" [10]. In most networking environments, RIP is not the preferred choice for routing as its time to converge and scalability are poor compared to Enhanced Internet Gateway Routing Protocol (EIGRP), Open Shortest Path First (OSPF), or Intermediate System to Intermediate System (IS-IS). However, it is easy to configure, because RIP does not require many parameters unlike other protocols. RIP is a classful routing protocol, this implies it does assume the default subnet mask during broadcast updates of the routing tables. RIP version 2(RIPv2) was introduced as a result of deficiencies of the original RIP specification, RIP version 2 was developed with the ability to carry subnet information during updates of routing tables, thus supporting Classless Inter-Domain Routing (CIDR) . To maintain backward compatibility, the hop count limit of 15 remained. RIPv2 has facilities to fully interoperate with the earlier specification [11]. RIPv2 multicasts the entire routing table to all adjacent routers at the address 224.0.0.9, as opposed to RIPv1 which uses broadcast. This is to avoid unnecessary load on hosts that do not participate in routing. 
A critical comparison of EIGRP and OSPF are routing protocols is shown below in table 0 from the Sudhanshun Bhat research, in this research, an attempt is made to also go beyond inherent routing metrics.

Table 0: Comparison of OSPF and EIGRP

\begin{tabular}{|c|c|c|}
\hline Metric & OSPF & EIGRP \\
\hline Scalability & 2 tier hierarchy, less scalable in general & Support many tiers and scalable \\
\hline Working on Full Mesh & $\begin{array}{l}\text { Works well with mesh group feature } \\
\text { but this increases configuration } \\
\text { complexity }\end{array}$ & $\begin{array}{l}\text { Works very poorly, and there is no mesh } \\
\text { group }\end{array}$ \\
\hline $\begin{array}{l}\text { Working on a Ring } \\
\text { Topology }\end{array}$ & $\begin{array}{l}\text { Ring is a hard topology for all protocols } \\
\text { but OSPF is better than EIGRP }\end{array}$ & $\begin{array}{l}\text { Not good, especially if ring is big due to } \\
\text { larger EIGRP query domain }\end{array}$ \\
\hline $\begin{array}{l}\text { Working on Hub and } \\
\text { Spoke }\end{array}$ & $\begin{array}{l}\text { Works poorly, require a lot of tuning } \\
\text { such as DR Priority }\end{array}$ & $\begin{array}{l}\text { Works very well. It requires minimum } \\
\text { tuning }\end{array}$ \\
\hline Fast Reroute Support & $\begin{array}{l}\text { Yes - IP FRR. Loop Free Alternate and } \\
\text { other IP FRR mechanisms supported }\end{array}$ & Yes - IP FRR and Feasible Successor(FS) \\
\hline Suitable on WAN & $\begin{array}{l}\text { Yes, OSPF as a place in the network is } \\
\text { suitable on the WAN }\end{array}$ & $\begin{array}{l}\text { Yes, EIGRP as a place in the network is } \\
\text { suitable on the WAN }\end{array}$ \\
\hline Suitable on Datacenter & $\begin{array}{l}\text { DC in general is a full mesh network.if } \\
\text { there is no other option than OSPF is } \\
\text { better }\end{array}$ & $\begin{array}{l}\text { DC, in general, is a full mesh network, } \\
\text { EIGRP is worse than OSPF }\end{array}$ \\
\hline $\begin{array}{l}\text { Suitable on Internet } \\
\text { Edge }\end{array}$ & $\begin{array}{l}\text { No, it is designed as an IGP routing } \\
\text { protocol, not as Inter domain routing } \\
\text { protocol }\end{array}$ & $\begin{array}{l}\text { No, it is designed as an IGP routing } \\
\text { protocol, not as Inter domain routing } \\
\text { protocol }\end{array}$ \\
\hline Standard Protocol & Yes IETF Standard & No, there is a draft but lack of Stub feature \\
\hline Stuff Experience & Very well known & Well known \\
\hline Overlay Tunnel Support & Yes & Yes \\
\hline $\begin{array}{l}\text { MPLS Traffic } \\
\text { Engineering Support }\end{array}$ & Yes with CSPF & $\begin{array}{l}\text { No, Although EIGRP Verbatim provides } \\
\text { manual TE capability }\end{array}$ \\
\hline Security & $\begin{array}{l}\text { It runs on top of IP, so protocol level is } \\
\text { not considered as secure }\end{array}$ & $\begin{array}{l}\text { It runs on top of IP. Open to remote } \\
\text { attacks same as OSPF }\end{array}$ \\
\hline $\begin{array}{l}\text { Suitable as Enterprise } \\
\text { IGP }\end{array}$ & Yes & Yes \\
\hline $\begin{array}{l}\text { Suitable as Service } \\
\text { Provider IGP }\end{array}$ & Yes & $\begin{array}{l}\text { No, it doesn't support Traffic Engineering } \\
\text { and other considerations }\end{array}$ \\
\hline Complexity & $\begin{array}{l}\text { Easy protocol but compare to EIGRP, } \\
\text { there are many LSA types, so more } \\
\text { complex }\end{array}$ & Easy protocol \\
\hline Metric & OSPF & EIGRP \\
\hline Policy Support & Good & Not so Good \\
\hline Resource Requirement & SPF requires more processing power & DUAL doesn't need much power \\
\hline Extendibility & $\begin{array}{l}\text { Not good, almost all the field of OSPF } \\
\text { packets are already reserved }\end{array}$ & Good, thanks to TLV support \\
\hline IPv6 Support & $\begin{array}{l}\text { Yes, though require new protocol which } \\
\text { is OSPFv3 }\end{array}$ & $\begin{array}{l}\text { Yes and no need a new protocol thanks to } \\
\text { TLV support }\end{array}$ \\
\hline Default Convergence & $\begin{array}{l}\text { Slow convergence with the default } \\
\text { timers, although it can be tuned }\end{array}$ & $\begin{array}{l}\text { Fast with Feasible Successor. Feasible } \\
\text { successor is an important for FC }\end{array}$ \\
\hline
\end{tabular}

Source: Sudhanshun Bhat, Cisco OSPF vs EIGRP 


\section{METHODOLOGY}

Literature typically classifies simulated research work from three perspectives in literature. One answer is that all talk of "simulation" and "numerical experiments" is purely hyperbolic or metaphoricalsimulation is nothing more and nothing less than using brute-force computational means to solve analytically intractable equations. A second view, in which the terms "simulation" and "numerical experiment" are taken quite literally, a simulation is a stand-in, or mimic, of a real-world system, and can therefore be experimented on just like any other experimental target. The third is the view that simulation is a brand new "third mode" of science, neither experimental nor theoretical[12]. This research specifically uses a simulator called Packet Tracer developed by cisco systems to technically generate and compare the output of routing protocols as they converge and route data. The comparison is done using the round trip time and time to live.

Round-trip time (RTT) is defined as the length of time taken for a signals to be sent plus the length of time it takes for an acknowledgement of the signal to be received. The time delay in this context also includes the propagation times for the paths between the two communication endpoints [13]. Time to live (TTL) on the other hand is a mechanism that limits the lifespan or lifetime of data in a computer or network. TTL is typically deployed either as a counter or timestamp in the data. In some instances, it may be attached to the data. The objective of implementing TTL is the effectively ensure that data is discarded or revalidated when the prescribed event count or the prescribed timespan has elapsed. The simulator is used to setup a network consisting of a set of computers on two separate local area networks interconnected via two optional paths consisting of four routers. The paths are segmented into paths one and two with bandwidths of $64 \mathrm{Kbps}$ and $1024000 \mathrm{Kbps}$ respectively. The configuration of OSPF and EIGRP are effected on all routers separately and connectivity between the two networks is tested. Specifically, connectivity is tested between PC2 and PC0, thus, 20.0.0.1/8 and 10.0.0.1/8. This test is done via paths one and two separately to record round trip times and time to live values for purposes of comparison. The ultimate comparison of the feedback depicts the efficiency of the specific routing protocols comparatively, the model of routers used was cisco 2900 at all routing points.

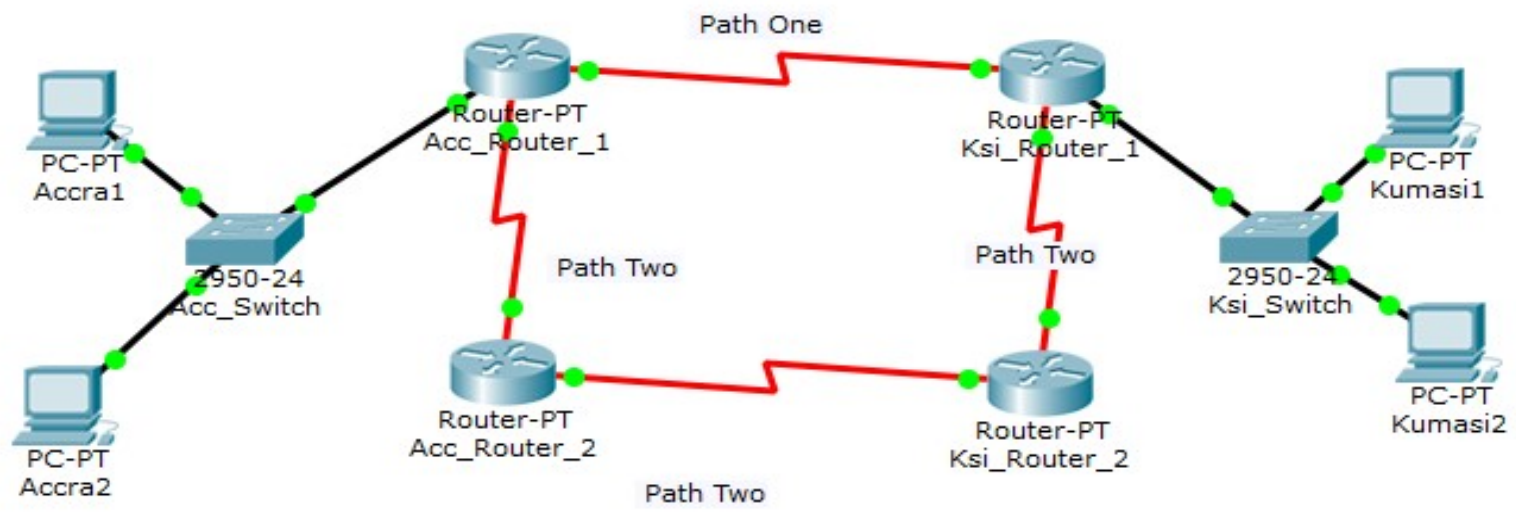

Figure 1: Topology of Lab Setup

Source: Author(s) 


\section{CONFIGURATION}

The specific machine names and their respective configurations are provided below, the essence is to provide a broad overview of the simulated environment.

Table 1: Address Configuration of Computers

\begin{tabular}{|l|l|l|}
\hline No & Computers & IP Address \\
\hline 1 & Accra1 & $10.0 .0 .1 / 8$ \\
\hline 2 & Accra2 & $10.0 .0 .2 / 8$ \\
\hline 3 & Kumasi1 & $20.0 .0 .1 / 8$ \\
\hline 4 & Kumasi2 & $20.0 .0 .2 / 8$ \\
\hline
\end{tabular}

Table 2: Configuration of Routers on RIP and EIGRP Platforms

\begin{tabular}{|c|c|c|c|}
\hline No & Router & Configuration for OSPF & Configuration for EIGRP \\
\hline 1 & Acc_Router_1 & $\begin{array}{l}\text { interface FastEthernet } 0 / 0 \\
\text { ip address 10.0.0.10 255.0.0.0 } \\
\text { duplex auto } \\
\text { speed auto } \\
\text { interface Serial2/0 } \\
\text { bandwidth } 64000 \\
\text { ip address } 30.0 .0 .1255 .0 .0 .0 \\
\text { clock rate } 2000000 \\
\text { interface Serial3/0 } \\
\text { bandwidth 1024000 } \\
\text { ip address 40.0.0.1 255.0.0.0 } \\
\text { clock rate 2000000 } \\
\text { router ospf } 1 \\
\text { network 10.0.0.0 0.255.255.255 area } 0 \\
\text { network 30.0.0.0 0.255.255.255 area } 0 \\
\text { network 40.0.0.0 0.255.255.255 area } 0\end{array}$ & $\begin{array}{l}\text { interface FastEthernet } 0 / 0 \\
\text { ip address 10.0.0.10 255.0.0.0 } \\
\text { duplex auto } \\
\text { speed auto } \\
\text { interface Serial2/0 } \\
\text { bandwidth } 64000 \\
\text { ip address } 30.0 .0 .1255 .0 .0 .0 \\
\text { clock rate } 2000000 \\
\text { interface Serial3/0 } \\
\text { bandwidth } 1024000 \\
\text { ip address } 40.0 .0 .1255 .0 .0 .0 \\
\text { clock rate } 2000000 \\
\text { router eigrp } 10 \\
\text { network 10.0.0.0 } \\
\text { network 30.0.0.0 } \\
\text { network 40.0.0.0 } \\
\text { auto-summary }\end{array}$ \\
\hline 2 & Ksi_Router_1 & $\begin{array}{l}\text { interface FastEthernet0/0 } \\
\text { ip address 20.0.0.10 255.0.0.0 } \\
\text { duplex auto } \\
\text { speed auto } \\
\text { interface Serial2/0 } \\
\text { bandwidth 64000 } \\
\text { ip address 30.0.0.2 255.0.0.0 } \\
\text { interface Serial3/0 } \\
\text { bandwidth 1024000 } \\
\text { ip address } 60.0 .0 .2 \text { 255.0.0.0 } \\
\text { clock rate } 2000000 \\
\text { router ospf } 1\end{array}$ & $\begin{array}{l}\text { interface FastEthernet } 0 / 0 \\
\text { ip address } 20.0 .0 .10 \text { 255.0.0.0 } \\
\text { duplex auto } \\
\text { speed auto } \\
\text { interface Serial2/0 } \\
\text { bandwidth } 64000 \\
\text { ip address } 30.0 .0 .2255 .0 .0 .0 \\
\text { interface Serial3/0 } \\
\text { bandwidth } 1024000 \\
\text { ip address } 60.0 .0 .2255 .0 .0 .0 \\
\text { router eigrp } 10 \\
\text { network } 20.0 .0 .0\end{array}$ \\
\hline
\end{tabular}




\begin{tabular}{|c|c|c|c|}
\hline & & $\begin{array}{l}\text { network 20.0.0.0 } 0.255 .255 .255 \text { area } 0 \\
\text { network 30.0.0.0 } 0.255 .255 .255 \text { area } 0 \\
\text { network 60.0.0.0 } 0.255 .255 .255 \text { area } 0\end{array}$ & $\begin{array}{l}\text { network 30.0.0.0 } \\
\text { network 60.0.0.0 } \\
\text { auto-summary }\end{array}$ \\
\hline $\mathrm{No}$ & Computers & IP Address & \\
\hline 3 & Acc_Router_2 & $\begin{array}{l}\text { interface Serial2/0 } \\
\text { bandwidth } 1024000 \\
\text { ip address } 40.0 .0 .2255 .0 .0 .0 \\
\text { interface Serial3/0 } \\
\text { bandwidth } 1024000 \\
\text { ip address } 50.0 .0 .1255 .0 .0 .0 \\
\text { clock rate } 2000000 \\
\text { router ospf } 1 \\
\text { network 50.0.0.0 } 0.255 .255 .255 \text { area } 0 \\
\text { network 40.0.0.0 } 0.255 .255 .255 \text { area } 0\end{array}$ & $\begin{array}{l}\text { interface Serial2/0 } \\
\text { bandwidth } 1024000 \\
\text { ip address 40.0.0.2 255.0.0.0 } \\
\text { interface Serial3/0 } \\
\text { bandwidth } 1024000 \\
\text { ip address 50.0.0.1 255.0.0.0 } \\
\text { clock rate 2000000 } \\
\text { router eigrp 10 } \\
\text { network 50.0.0.0 } \\
\text { network 40.0.0.0 } \\
\text { auto-summary }\end{array}$ \\
\hline 4 & Ksi_Router_2 & $\begin{array}{l}\text { interface Serial2/0 } \\
\text { bandwidth } 1024000 \\
\text { ip address } 50.0 .0 .2255 .0 .0 .0 \\
\text { interface Serial3/0 } \\
\text { bandwidth } 1024000 \\
\text { ip address } 60.0 .0 .1255 .0 .0 .0 \\
\text { router ospf } 1 \\
\text { network } 50.0 .0 .00 .255 .255 .255 \text { area } 0 \\
\text { network } 60.0 .0 .00 .255 .255 .255 \text { area } 0\end{array}$ & $\begin{array}{l}\text { interface Serial2/0 } \\
\text { bandwidth } 1024000 \\
\text { ip address 50.0.0.2 255.0.0.0 } \\
\text { interface Serial3/0 } \\
\text { bandwidth } 1024000 \\
\text { ip address } 60.0 .0 .1255 .0 .0 .0 \\
\text { clock rate 2000000 } \\
\text { router eigrp 10 } \\
\text { network 50.0.0.0 } \\
\text { network 60.0.0.0 } \\
\text { auto-summary }\end{array}$ \\
\hline
\end{tabular}




\section{RESULTS}

The configurations shown in table 1 led to the generation of the routing tables depicted in tables 2 and 3 below;

Applicable Codes for Displayed Routes

C - connected, S - static, I - IGRP, R - RIP, M - mobile, B - BGP, D - EIGRP, EX - EIGRP external, O - OSPF, IA - OSPF inter area, N1 - OSPF NSSA external type 1, N2 - OSPF NSSA external type 2, E1 - OSPF external type 1, E2 - OSPF external type 2, E - EGP, i - IS-IS, L1 - IS-IS level-1, L2 - IS-IS level-2, ia - IS-IS inter area, * - candidate default, U - per-user static route, o - ODR, P - periodic downloaded static route

Table 2: Routing Tables for Configuration

\begin{tabular}{|c|c|c|}
\hline No & Router & OSPF Routing Table \\
\hline 1 & Acc_Router_1 & $\begin{array}{l}\text { C } 10.0 .0 .0 / 8 \text { is directly connected, FastEthernet } 0 / 0 \\
\text { O } 20.0 .0 .0 / 8 \text { [110/2] via } 30.0 .0 .2,00: 22: 49 \text {, Serial } 2 / 0 \\
\text { C } 30.0 .0 .0 / 8 \text { is directly connected, Serial } 2 / 0 \\
\text { C } 40.0 .0 .0 / 8 \text { is directly connected, Serial3/0 } \\
\text { O } 50.0 .0 .0 / 8 \text { [110/2] via } 40.0 .0 .2,00: 23: 49 \text {, Serial3/0 } \\
\text { O } 60.0 .0 .0 / 8 \text { [110/2] via } 30.0 .0 .2,00: 22: 49 \text {, Serial2/0 }\end{array}$ \\
\hline 2 & Ksi_Router_1 & $\begin{array}{l}\text { O } 10.0 .0 .0 / 8 \text { [110/2] via 30.0.0.1, 00:23:30, Serial2/0 } \\
\text { C } 20.0 .0 .0 / 8 \text { is directly connected, FastEthernet } 0 / 0 \\
\text { C } 30.0 .0 .0 / 8 \text { is directly connected, Serial2/0 } \\
\text { O } 40.0 .0 .0 / 8 \text { [110/2] via } 30.0 .0 .1,00: 23: 30 \text {, Serial } 2 / 0 \\
\text { O } 50.0 .0 .0 / 8 \text { [110/2] via } 60.0 .0 .1,00: 23: 00, \text { Serial3/0 } \\
\text { C } 60.0 .0 .0 / 8 \text { is directly connected, Serial3/0 }\end{array}$ \\
\hline 3 & Acc_Router_2 & $\begin{array}{l}\text { O } 10.0 .0 .0 / 8[110 / 2] \text { via } 40.0 .0 .1,00: 25: 43 \text {, Serial2/0 } \\
\text { O } 20.0 .0 .0 / 8[110 / 3] \text { via } 50.0 .0 .2,00: 24: 10 \text {, Serial3/0 } \\
{[110 / 3] \text { via } 40.0 .0 .1,00: 24: 10, \text { Serial2/0 }} \\
\text { O } 30.0 .0 .0 / 8[110 / 2] \text { via } 40.0 .0 .1,00: 25: 43 \text {, Serial2/0 } \\
\text { C } 40.0 .0 .0 / 8 \text { is directly connected, Serial2/0 } \\
\text { C } 50.0 .0 .0 / 8 \text { is directly connected, Serial3/0 } \\
\text { O } 60.0 .0 .0 / 8 \text { [110/2] via 50.0.0.2, } 00: 24: 10, \text { Serial3/0 }\end{array}$ \\
\hline 4 & Ksi_Router_2 & $\begin{array}{l}\text { O } 10.0 .0 .0 / 8[110 / 3] \text { via } 50.0 .0 .1,00: 24: 48, \text { Serial2/0 } \\
{[110 / 3] \text { via } 60.0 .0 .2,00: 24: 48, \text { Serial3/0 }} \\
\text { O } 20.0 .0 .0 / 8[110 / 2] \text { via } 60.0 .0 .2,00: 24: 48 \text {, Serial3/0 } \\
\text { O } 30.0 .0 .0 / 8[110 / 2] \text { via } 60.0 .0 .2,00: 24: 48 \text {, Serial3/0 } \\
\text { O } 40.0 .0 .0 / 8[110 / 2] \text { via } 50.0 .0 .1,00: 24: 48 \text {, Serial2/0 } \\
\text { C } 50.0 .0 .0 / 8 \text { is directly connected, Serial2/0 } \\
\text { C } 60.0 .0 .0 / 8 \text { is directly connected, Serial3/0 }\end{array}$ \\
\hline
\end{tabular}


Table 3: Routing Table for EIGRP Configuration

\begin{tabular}{|c|c|c|}
\hline $\mathrm{No}$ & Router & EIGRP Routing Table \\
\hline 1 & Acc_Router_1 & $\begin{array}{l}\text { C } 10.0 .0 .0 / 8 \text { is directly connected, FastEthernet } 0 / 0 \\
\text { D } 20.0 .0 .0 / 8 \text { [90/554496] via 30.0.0.2, 00:07:00, Serial2/0 } \\
\text { C } 30.0 .0 .0 / 8 \text { is directly connected, Serial2/0 } \\
\text { C } 40.0 .0 .0 / 8 \text { is directly connected, Serial3/0 } \\
\text { D } 50.0 .0 .0 / 8[90 / 1026304] \text { via 40.0.0.2, 00:07:02, Serial3/0 } \\
\text { D } 60.0 .0 .0 / 8[90 / 1063936] \text { via 30.0.0.2, } 00: 07: 00, \text { Serial2/0 }\end{array}$ \\
\hline 2 & Kum_Router_1 & $\begin{array}{l}\text { D } 10.0 .0 .0 / 8 \text { [90/554496] via 30.0.0.1, 00:07:40, Serial2/0 } \\
\text { C } 20.0 .0 .0 / 8 \text { is directly connected, FastEthernet } 0 / 0 \\
\text { C } 30.0 .0 .0 / 8 \text { is directly connected, Serial2/0 } \\
\text { D } 40.0 .0 .0 / 8 \text { [90/1063936] via 30.0.0.1, 00:07:40, Serial2/0 } \\
\text { D 50.0.0.0/8 [90/1026304] via } 60.0 .0 .1,00: 07: 42, \text { Serial3/0 } \\
\text { C } 60.0 .0 .0 / 8 \text { is directly connected, Serial3/0 }\end{array}$ \\
\hline 3 & Acc_Router_2 & $\begin{array}{l}\text { D } 10.0 .0 .0 / 8[90 / 540160] \text { via } 40.0 .0 .1,00: 06: 23, \text { Serial2/0 } \\
\text { D } 20.0 .0 .0 / 8[90 / 1052160] \text { via } 50.0 .0 .2,00: 06: 23 \text {, Serial3/0 } \\
\text { D } 30.0 .0 .0 / 8[90 / 1063936] \text { via 40.0.0.1, 00:06:23, Serial2/0 } \\
\text { C } 40.0 .0 .0 / 8 \text { is directly connected, Serial2/0 } \\
\text { C } 50.0 .0 .0 / 8 \text { is directly connected, Serial3/0 } \\
\text { D } 60.0 .0 .0 / 8[90 / 1026304] \text { via } 50.0 .0 .2,00: 06: 23, \text { Serial3/0 }\end{array}$ \\
\hline 4 & Ksi_Router_2 & $\begin{array}{l}\text { D } 10.0 .0 .0 / 8[90 / 1052160] \text { via } 50.0 .0 .1,00: 05: 33, \text { Serial2/0 } \\
\text { D } 20.0 .0 .0 / 8[90 / 540160] \text { via } 60.0 .0 .2,00: 05: 33, \text { Serial3/0 } \\
\text { D } 30.0 .0 .0 / 8[90 / 1063936] \text { via } 60.0 .0 .2,00: 05: 31, \text { Serial3/0 } \\
\text { D 40.0.0.0/8 [90/1026304] via 50.0.0.1, 00:05:33, Serial2/0 } \\
\text { C 50.0.0.0/8 is directly connected, Serial2/0 } \\
\text { C 60.0.0.0/8 is directly connected, Serial3/0 }\end{array}$ \\
\hline
\end{tabular}

The results obtained from the connectivity tests are as detailed below;

\subsection{OSPF Results for Path One}

Packet Tracer PC Command Line 1.0

$\mathrm{C}: \mid>$ tracert 10.0.0.1

Tracing route to 10.0.0.1 over a maximum of 30 hops:

$\begin{array}{lllll}1 & 1 \mathrm{~ms} & 0 \mathrm{~ms} & 0 \mathrm{~ms} & 20.0 .0 .10 \\ 2 & 3 \mathrm{~ms} & 1 \mathrm{~ms} & 2 \mathrm{~ms} & 30.0 .0 .1 \\ 3 & 0 \mathrm{~ms} & 0 \mathrm{~ms} & 1 \mathrm{~ms} & 10.0 .0 .1\end{array}$

Trace complete.

$\mathrm{C}: \mid>\operatorname{ping} 10.0 .0 .1$ 
Pinging 10.0.0.1 with 32 bytes of data:

Reply from 10.0.0.1: bytes $=32$ time $=2 \mathrm{~ms}$ TTL $=126$

Reply from 10.0.0.1: bytes $=32$ time $=1 \mathrm{~ms}$ TTL $=126$

Reply from 10.0.0.1: bytes $=32$ time $=1 \mathrm{~ms}$ TTL $=126$

Reply from 10.0.0.1: bytes $=32$ time $=1 \mathrm{~ms}$ TTL $=126$

Ping statistics for 10.0.0.1:

Packets: Sent $=4$, Received $=4$, Lost $=0$ (0\% loss), Approximate round trip times in milli-seconds:

Minimum $=1 \mathrm{~ms}$, Maximum $=2 \mathrm{~ms}$, Average $=1 \mathrm{~ms}$

\subsection{OSPF Results for Path Two}

C: $>$ tracert 10.0.0.1

Tracing route to 10.0.0.1 over a maximum of 30 hops:

$\begin{array}{rlrrr}1 & * & 0 \mathrm{~ms} & 0 \mathrm{~ms} & 20.0 \cdot 0.10 \\ 2 & 1 \mathrm{~ms} & 0 \mathrm{~ms} & 1 \mathrm{~ms} & 60.0 \cdot 0.1 \\ 3 & 1 \mathrm{~ms} & 2 \mathrm{~ms} & 2 \mathrm{~ms} & 50.0 .0 .1 \\ 4 & 2 \mathrm{~ms} & 1 \mathrm{~ms} & 3 \mathrm{~ms} & 40.0 .0 .1 \\ 5 & * & 12 \mathrm{~ms} & 11 \mathrm{~ms} & 10.0 \cdot 0.1\end{array}$

Trace complete.

C: $\mid>$ ping 10.0.0.1

Pinging 10.0.0.1 with 32 bytes of data:

Reply from 10.0.0.1: bytes $=32$ time $=3 \mathrm{~ms}$ TTL $=124$

Reply from 10.0.0.1: bytes $=32$ time $=10 \mathrm{~ms}$ TTL $=124$

Reply from 10.0.0.1: bytes $=32$ time $=12 \mathrm{~ms}$ TTL $=124$

Reply from 10.0.0.1: bytes $=32$ time $=11 \mathrm{~ms}$ TTL $=124$

Ping statistics for 10.0.0.1:

Packets: Sent $=4$, Received $=4$, Lost $=0$ (0\% loss), Approximate round trip times in milli-seconds:

Minimum $=3 \mathrm{~ms}$, Maximum $=12 \mathrm{~ms}$, Average $=9 \mathrm{~ms}$

\section{3: EIGRP Results via Path One}

$\mathrm{C}: \mid>$ tracert 10.0.0.1

Tracing route to 10.0.0.1 over a maximum of 30 hops:

$10 \mathrm{~ms} 0 \mathrm{~ms} 0 \mathrm{~ms} 20.0 \cdot 0.10$

$21 \mathrm{~ms} 0 \mathrm{~ms} 1 \mathrm{~ms} 30.0 .0 .1$

3 * $1 \mathrm{~ms} 0 \mathrm{~ms}$ 10.0.0.1

Trace complete. 
C: $\mid>$ ping 10.0.0.1

Pinging 10.0.0.1 with 32 bytes of data:

Reply from 10.0.0.1: bytes $=32$ time $=2 \mathrm{~ms}$ TTL $=126$

Reply from 10.0.0.1: bytes $=32$ time $=1 \mathrm{~ms}$ TTL $=126$

Reply from 10.0.0.1: bytes $=32$ time $=1 \mathrm{~ms}$ TTL $=126$

Reply from 10.0.0.1: bytes $=32$ time $=1 \mathrm{~ms}$ TTL $=126$

Ping statistics for 10.0.0.1:

Packets: Sent $=4$, Received $=4$, Lost $=0(0 \%$ loss $)$,

Approximate round trip times in milli-seconds:

Minimum $=1 \mathrm{~ms}$, Maximum $=2 \mathrm{~ms}$, Average $=1 \mathrm{~ms}$

\subsection{EIGRP Results via Path Two}

C: $>>$ tracert 10.0.0.1

Tracing route to 10.0.0.1 over a maximum of 30 hops:

$10 \mathrm{~ms} 0 \mathrm{~ms} 0 \mathrm{~ms} 20.0 .0 .10$

$22 \mathrm{~ms} 0 \mathrm{~ms} 0 \mathrm{~ms} 60.0 .0 .1$

$31 \mathrm{~ms} 2 \mathrm{~ms} 2 \mathrm{~ms} 50.0 .0 .1$

$40 \mathrm{~ms} 1 \mathrm{~ms} 1 \mathrm{~ms} 40.0 .0 .1$

$512 \mathrm{~ms} 11 \mathrm{~ms} 11 \mathrm{~ms}$ 10.0.0.1

Trace complete.

C: $\mid>$ ping 10.0.0.1

Pinging 10.0.0.1 with 32 bytes of data:

Reply from 10.0.0.1: bytes $=32$ time $=3 \mathrm{~ms}$ TTL $=124$

Reply from 10.0.0.1: bytes $=32$ time $=5 \mathrm{~ms}$ TTL $=124$

Reply from 10.0.0.1: bytes $=32$ time $=6 \mathrm{~ms}$ TTL $=124$

Reply from 10.0.0.1: bytes $=32$ time $=11 \mathrm{~ms}$ TTL $=124$

Ping statistics for 10.0.0.1:

Packets: Sent $=4$, Received $=4$, Lost $=0(0 \%$ loss $)$, Approximate round trip times in milli-seconds:

Minimum $=3 \mathrm{~ms}$, Maximum $=11 \mathrm{~ms}$, Average $=6 \mathrm{~ms}$

Table 4: Empirical Comparison Simulation Results

\begin{tabular}{|l|c|c|}
\hline \multicolumn{1}{|c|}{ Metric } & $\begin{array}{c}\text { OSPF Platform Values } \\
\text { (milli-seconds) }\end{array}$ & $\begin{array}{c}\text { EIGRP Platform Values } \\
\text { (milli-seconds) }\end{array}$ \\
\hline Path One Time to Live (Average) & 1 & 1 \\
\hline Path One Round Trip (Average) & 1 & 1 \\
\hline Path Two Time to Live (Average) & 11 & 11 \\
\hline Path Two Round Trip (Average) & 9 & 6 \\
\hline
\end{tabular}


Table 4 shows a summarized comparison of the test output, the metrics for comparison are the average time to live and average round trip from the "tracert" and "ping" results. Evidently, the average time to live is consistent by default for both routing protocols however, the round trip produces some varying results. EIGRP tends to produce a quicker round trip.

\section{CONCLUSION}

An empirically comparison between the two routing protocols Open Shortest Path First (OSPF) and Enhanced Interior Gateway Routing Protocol (EIGRP) has been successfully completed. Having developed a simulated environment with a network setup to test and compare overall round trip times and time to live values experienced on a single topology and different bandwidth paths, the results of the experiment showed that EIGRP provides faster transmission and response times as compared to OSPF implementation under the simulated environment in the event of all conditions are equal. Compared to earlier research work done on different topologies but same routing protocols, this research output confirms the notion that EIGRP performs better than OSPF beyond their inherent routing metrics. Further research may be carried out on more complex topologies to ascertain or confirm this outcome. 


\section{REFERENCES}

[1] S.U. Masruroh, A. Fiade \& M.F. Iman., Performance evaluation of routing protocol RIPv2, OSPF, EIGRP with BGP,2017 International Conference on Innovative and Creative Information Technology (ICITech), vol. 2, no. 9, (2017) 1-9,

[2] D.F. Asigbe, A.M. Mustapha, C.M. Agbesi, F.E. Botchey, S.K. Anibrika \& C. Somuah, Performance Analysis Of Interior Gateway Routing Protocol (Eigrp) Over Open Shortest Path First (OSPF) Protocol, International Journal of Scientific \& Technology Research Volume 5, Issue 09, ISSN 2277-8616, (2016) 111-117

[3] L. Wang, Y. Chang, K. Cheng. Electronic Design Automation: Synthesis, Verification, and Test. Morgan Kaufmann. ISBN 0080922007 (2009) 204.

[4] J. Seeger. and A. Khanna., Reducing Routing Overhead in a Growing DDN, MILCOMM (1986)

[5] V. Fuller and T. Li. Classless Inter-domain Routing (CIDR): The Internet Address Assignment and Aggregation Plan. doi:10.17487/RFC4632, (2006)

[6] J. Doyle \& J. Carroll, CCIE Professional Development: Routing TCP/IP Volume I, Second Edition. ciscopress.com. ISBN 9781587052026. (2005) 169.

[7] T. Lammle, CCNA Cisco Certified Network Associate Study Guide (Sixth ed.), Indianapolis, Indiana: Wiley Publishing, ISBN 978-0-470-11008-9. (2007)

[8] I. Pepelnjak, EIGRP Network Design Solutions: The Definitive Resource for EIGRP Design, Deployment, and Operation. (2000)

[9] Moy, J. (April 1998). "OSPF Version 2". The Internet Society. OSPFv2. Retrieved 2007-09-28.

[10]Balchunas, Aaron. "Routing Information Protocol (RIP v1.03)" (PDF). http://www.routeralley.com. Retrieved 25 April 2014.

[11]P. Almquist, Towards Requirements for IP Routers, RFC 1716 2. Atkinson R. and Fanto M.(2007),

[12] E. Winsberg, Methodology for a Virtual World, Philosophy of Science, Vol. 70, No. 1 (2003) 105-125

[13]D.E. Comer, (Internetworking with TCP/IP - Principles, Protocols and Architecture (4th ed.). Prentice Hall. ISBN 0-13-018380-6. (2000) 226 


\begin{abstract}
About the Authors
Dr. Paul Asante Danquah is an IT professional and a Research Scientist who holds a BSc HONS in Computing, MSc in Information Security and a PhD in IT (Specialized in Cybercrime) from the University of Greenwich UK, Anglia Ruskin University UK and Open University Malaysia respectively. He has various industry certifications, some of which are Certified Ethical Hacker (CEH), Data Center Infrastructure Expert (DCIE), Cisco Certified Network Professional (CCNP) and Microsoft Certified Systems Engineer (MCSE). Dr. Paul Danquah has worked in various capacities over the last 20 years, these range from Programmer, Network Engineer, IT Manager and Technical Director of various organizations.
\end{abstract}

Ing. Victor Gordon is a tech-savvy Telecommunications Engineer and a Chief Technologist at the Council for Scientific and Industrial Research in Accra. He currently is a Ph.D. student in ICT at the OUM/AIT in Accra. He also holds an MSc in Telecommunications Engineering and IT from the University of Applied Sciences Technikum Wien in Austria and a BSc HONS in Computer Engineering from the Kwame Nkrumah University of Science and Technology in Ghana. Ing. Gordon has worked in various capacities over the past 18 years, ranging from Telecoms engineer, IT Project/program manager, and technical coordinator of various organizations.

Peh Benjamin is a Research Technologist with the Communications Division of the Institute for Scientific and Technological Information (INSTI) at the Council for Scientific and Industrial Research (CSIR) Ghana. He has about 9 years' progressive experience in IT, six of which was spent in the Rural Banking Industry as Systems Administrator and later as Deputy IT Manager. Benjamin Peh has relevant knowledge in web content management, data analysis, information systems security, hardware security, and big data knowledge. He also holds a Master of Science degree in Management Information Systems (MIS) from Coventry University UK, a BSc in Computer Science from the Kwame Nkrumah University of Science and Technology Ghana, and a Certificate in Certified Information Systems Auditor (CISA) from the Ghana Institute of Management and Public Administration (GIMPA). 